\title{
Interaction between Overtraining and the Interindividual Variability May (Not) Trigger Muscle Oxidative Stress and Cardiomyocyte Apoptosis in Rats
}

\author{
Rodrigo Luiz Perroni Ferraresso, ${ }^{1}$ Renato Buscariolli de Oliveira, ${ }^{1}$ Denise Vaz Macedo, ${ }^{1}$ \\ Lázaro Alessandro Soares Nunes, ${ }^{1}$ René Brenzikofer, ${ }^{2}$ Danilo Damas, ${ }^{3}$ and Rodrigo Hohl ${ }^{1}$ \\ ${ }^{1}$ Laboratory of Exercise Biochemistry (LABEX), Biology Institute, University of Campinas (UNICAMP), \\ 13083-970 Campinas, SP, Brazil \\ ${ }^{2}$ Laboratory of Instrumentation for Biomechanics (LIB), Faculty of Physical Education (FEF), University of Campinas (UNICAMP), \\ 13083-970 Campinas, SP, Brazil \\ ${ }^{3}$ Laboratory of Histology, Biology Institute, University of Campinas (UNICAMP), 13083-970 Campinas, SP, Brazil
}

Correspondence should be addressed to Rodrigo Hohl, hohlrodrigo@gmail.com

Received 9 April 2012; Accepted 16 April 2012

Academic Editor: Michalis G. Nikolaidis

Copyright ( $) 2012$ Rodrigo Luiz Perroni Ferraresso et al. This is an open access article distributed under the Creative Commons Attribution License, which permits unrestricted use, distribution, and reproduction in any medium, provided the original work is properly cited.

\begin{abstract}
Severe endurance training (overtraining) may cause underperformance related to muscle oxidative stress and cardiomyocyte alterations. Currently, such relationship has not been empirically established. In this study, Wistar rats $(n=19)$ underwent eight weeks of daily exercise sessions followed by three overtraining weeks in which the daily frequency of exercise sessions increased. After the 11th training week, eight rats exhibited a reduction of $38 \%$ in performance (nonfunctional overreaching group (NFOR)), whereas eleven rats exhibited an increase of $18 \%$ in performance (functional overreaching group (FOR)). The red gastrocnemius of NFOR presented significantly lower citrate synthase activity compared to FOR, but similar to that of the control. The activity of mitochondrial complex IV in NFOR was lower than that of the control and FOR. This impaired mitochondrial adaptation in NFOR was associated with increased antioxidant enzyme activities and increased lipid peroxidation (in muscle and plasma) relative to FOR and control. Cardiomyocyte apoptosis was higher in NFOR. Plasma creatine kinase levels were unchanged. We observed that some rats that presented evidence of muscle oxidative stress are also subject to cardiomyocyte apoptosis under endurance overtraining. Blood lipid peroxides may be a suitable biomarker for muscle oxidative stress that is unrelated to severe muscle damage.
\end{abstract}

\section{Introduction}

The upper limit of human sports performance has yet to be identified. To maximize physical performance, athletes and coaches manipulate training load through adjustments in duration, frequency, and intensity or through a reduction of the regenerative period. However, a cumulative imbalance between exercise load and recovery can lead to persistent, undesirable underperformance associated with training and/or nontraining stress, which is generally referred to as overtraining (OT).

Sports science researchers have used a variety of terminologies to describe both the means and the consequences of OT [1]. In 2006, to encourage a consensus among researchers in the field, the European College of Sport Science defined OT as a continuous process of intense training that can generate different performance states [2]. The functional overreaching (FOR) state is characterized by performance maintenance or by an increase in performance after a brief recovery period of days to weeks. The nonfunctional overreaching (NFOR) state is characterized by a prolonged decay of performance that is reversed only by a long regenerative period of weeks to months. Finally, overtraining syndrome (OTS) is the most extreme state of OT; performance recovery in OTS may take years to occur or may never occur. 
Lehmann et al. [3] reported that individual variability in recovery potential, exercise capacity, stress tolerance, and training tolerance explains the diverse vulnerabilities of athletes to OT under identical training stimuli. However, the metabolic and physiological factors responsible for the varying individual responses to OT and the causes of persistent underperformance are not well understood. Therefore, we have investigated the potential effects of endurance OT in Wistar rats using a standardized, 11-week treadmill endurance OT regimen [4]. Using this OT protocol, we observed lower citrate synthase (CS) activity in the red gastrocnemius (RG) muscle in rats that displayed a longterm reduction of performance in their training regimen [4]. In contrast, an increase in CS activity is an expected positive adaptation to endurance training as a known marker of mitochondrial oxidative capacity [5].

It has been proposed that $0.1 \%$ of the $\mathrm{O}_{2}$ consumed by the mitochondria is converted to superoxide anions $\left(\mathrm{O}_{2}{ }^{--}\right)$[6]. Therefore, exercise may increase reactive oxygen species (ROS) levels because it increases whole-body and tissue rates of oxygen consumption [7]. The ROS generated during exercise can reduce the ATP yield in mitochondria by potentially damaging protein complexes in the electron transport chain, mitochondrial enzymes, membrane lipids or mitochondrial DNA [8-11] Nevertheless, a series of enzymatic and nonenzymatic antioxidants limit the biological activity of ROS inside the mitochondria and in the cytosol [12], and, accordingly, it was shown [13] that contractile activity in isolated muscle is related to an immediate enzymatic antioxidant response.

Chronic endurance training, however, does not result in a predictable adaptation of antioxidant enzyme activity in parallel to oxidative capacity in rat skeletal muscle [1417]. Therefore, persistently high concentrations of ROS during severe endurance training can overwhelm cellular defense mechanisms and generate oxidative stress [18]. In this sense, the relationship between oxidative stress and underperformance in OT was previously proposed [19].

Severe endurance exercise can also increase the production of ROS in cardiac muscle [20]. Studies of ultraendurance activities have highlighted cardiac risks, such as the transient loss of ventricular function, increased heart tissue damage and the subsequent appearance of myocardial injury biomarkers in the blood $[21,22]$. In rats, treadmill running to exhaustion was associated with increased deletion of mitochondrial DNA (mtDNA ${ }^{4834}$ ) and increased apoptosis in the left ventricle (LV) [23]. It was thus shown that $\mathrm{H}_{2} \mathrm{O}_{2}$ and $\mathrm{O}_{2}{ }^{\bullet-}$-induce apoptosis [24] by opening the permeability transition pore and triggering the release of proapoptotic proteins into the cytosol [25]. For obvious reasons, we have not found studies reporting possible morphological modifications or an altered redox status in the cardiac tissue of athletes subjected to OT that might correlate changes to the myocardial tissue structure with underperformance. Unlike in skeletal muscle, the impairment of cardiac function by severe alterations of cardiac tissue structure can not only decrease performance but also can be fatal. Therefore, it is essential to establish specific blood biomarkers for severe endurance training to indicate individual intolerance to training regimens and to provide empirical evidence for the risks assumed [26].

The aim of this study was to provide support for the hypothesis that muscular oxidative stress and lowered mitochondrial capacity are metabolic features that underlie persistent underperformance due to endurance OT. Furthermore, we investigated the potentially dangerous effect of endurance OT on heart tissue, targeting the relationship between individual vulnerability to muscle oxidative stress, cardiac apoptosis, and histological alterations.

\section{Materials and Methods}

The rationale for all methodological procedures concerning the development and the characterization of the OT animal model used in this study is published elsewhere [4]. We present here sufficient description for an independent reading.

2.1. Animals. Fifty-six 21-day-old male albino Wistar rats were acquired from the Multidisciplinary Center for Biological Investigation on Laboratory Animal Science (CEMIB), UNICAMP. The animals were housed in a climate-controlled environment at $25 \pm 1^{\circ} \mathrm{C}$ with an inverted $12 \mathrm{~h}$ light-dark cycle and were fed ad libitum. The experimental protocols were approved by the Animal Experimentation Ethics Committee of the Institute of Biology (IB)-UNICAMP.

When they were 60 days old, the rats were adapted to the treadmill for two weeks prior to beginning the training protocol. During the adaptation phase, the rats were placed on a treadmill 5 days/week for 10 minutes at a speed of $12 \mathrm{~m} / \mathrm{min}$. This initial training distinguished the animals that ran voluntarily $(n=50)$ from the rats that refused to run $(n=6)$ to ensure that only animals that ran were included in the study.

2.2. Training Protocol. The training protocol was designed to induce a training-to-OT continuum as evaluated by six performance tests (T1 to T6) (Table 1). A motorized treadmill with twelve individual lanes and no inclination was used. A shock grid at the back of the treadmill provided a mild shock $(1.5 \mathrm{~mA})$ if the pace of the rats fell below the treadmill speed. The training week consisted of five consecutive days of training sessions followed by two days of rest. The amount of training in minutes of each training session was individually quantified. The animals were allowed to recover for 24 hours between training sessions during the adaptative training phases (AT1 and AT2). The recovery period between sessions was gradually decreased during $\mathrm{T} 2 \mathrm{x}, \mathrm{T} 3 \mathrm{x}$, and $\mathrm{T} 4 \mathrm{x}$ (Table 1).

2.3. Performance Test. All tests were performed 60 hours after the last training session of the week (between 1:00 pm and $5: 00 \mathrm{pm}$ ). The tests began with the animals running on the treadmill at an initial speed of $12 \mathrm{~m} / \mathrm{min}$. Every 2 minutes, the speed was increased by $1 \mathrm{~m} / \mathrm{min}$ until $20 \mathrm{~m} / \mathrm{min}$ was reached. After that, the speed was increased by $2 \mathrm{~m} / \mathrm{min}$ every 3 minutes until exhaustion, which was defined as the time at which the animals touched the shock grid five times in one 
Table 1: Training Protocol.

\begin{tabular}{lcccccc}
\hline Experimental weeks & Training phases & Test number & $\begin{array}{c}\text { Training speed } \\
(\mathrm{m} / \mathrm{min})\end{array}$ & $\begin{array}{c}\text { Training time } \\
(\mathrm{min})\end{array}$ & $\begin{array}{c}\text { Number of daily } \\
\text { sessions }\end{array}$ & $\begin{array}{c}\text { Recovery between } \\
\text { training sessions (h) }\end{array}$ \\
\hline \multirow{3}{*}{ 1st } & Acclimatization & T1 & $(-)$ & $(-)$ & $(-)$ & $(-)$ \\
2sd & AT1 & no tests & 15 & 20 & 1 & 24 \\
3th & AT1 & no tests & 20 & 30 & 1 & 24 \\
4th & AT1 & no tests & 22,5 & 45 & 1 & 24 \\
5th to 7th & AT1 & T2 & 25 & 60 & 1 & 24 \\
8th & AT2 & no tests & 25 & 60 & 1 & 24 \\
9th & AT2 & T3 & 25 & 60 & 1 & 4 \\
10th & T2x & T4 & 25 & 60 & 2 & 3 \\
11th & T3x & T5 & 25 & 60 & 3 & 2 \\
\hline
\end{tabular}

AT1: adaptative training 1. AT2: adaptative training 2. T2x, T3x, T4x: training week w/2, 3, and 4 daily sessions.

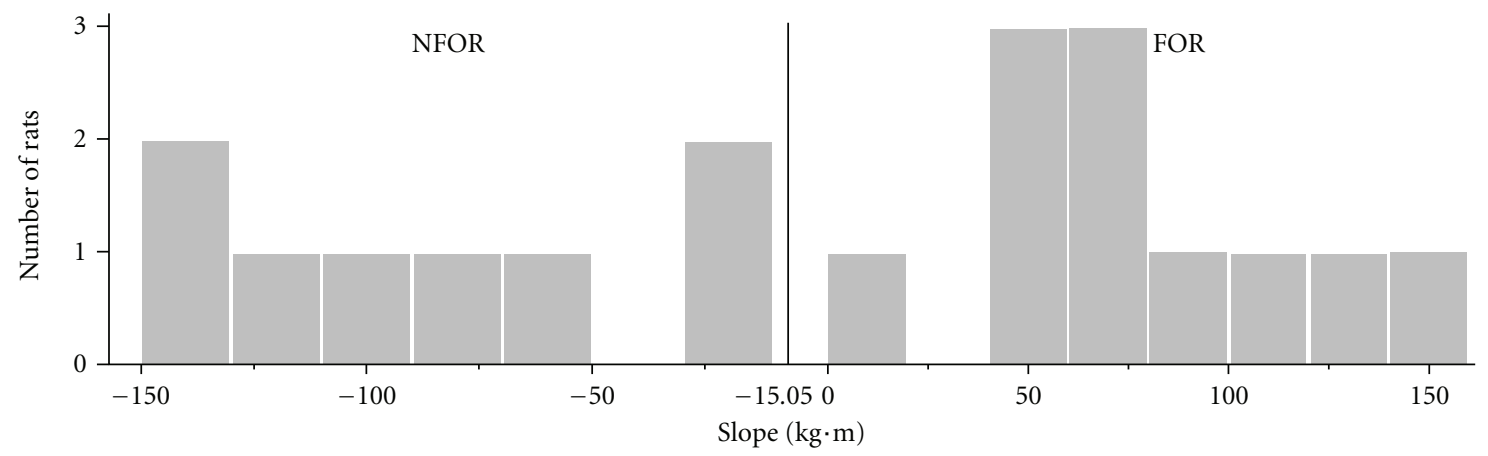

Figure 1: Histogram of the Pr slopes of the NFOR $(n=8)$ and FOR $(n=11)$ groups.

minute. The body weight of the animals was measured before each performance test.

2.4. Performance Quantification. To better evaluate the effect of training over time, we quantified animal performance using a mass-dependent model. This calculation allows the performance of each rat to be measured by a quantity that is proportional to the mechanical work performed by the rat as it runs on the treadmill, specifically, power times distance, as shown in (1):

$$
\operatorname{Pr}=\Sigma \operatorname{Pr}_{i}=\Sigma m V_{i} T_{i}=\Sigma m D_{i}=m D,
$$

where $(\mathrm{Pr})$ represents the rat's performance, $\left(\mathrm{Pr}_{i}\right)$ is the performance of the rat at each stage $(i),(m)$ is the body mass, $\left(V_{i}\right)$ is the stage velocity, $\left(T_{i}\right)$ is the stage running time, $\left(D_{i}\right)$ is the stage distance; and $(D)$ is the total distance covered by the rat during the test. In this paper, Pr will be expressed in kilograms multiplied by meters $(\mathrm{kg} \cdot \mathrm{m})$.

2.5. Animal Groups. Only those rats with $\operatorname{Pr}$ values that ranged between 70 and $230 \mathrm{~kg} \cdot \mathrm{m}$ (28 out of 50 running rats) in test 1 (T1; Table 1 ) were selected for the study. The rejected rats were transferred to other studies. A control group ( $\mathrm{CO}, n=9$ ) was randomly selected from among the
28 rats chosen for this study. During the 11 weeks of training, the animals of the $\mathrm{CO}$ group were subjected to $10 \mathrm{~min}$ of running at $12 \mathrm{~m} / \mathrm{min}$ twice a week to become accustomed to the treadmill and handling. The other 19 rats were subjected to the training protocol and were finally divided in two groups: nonfunctional overreaching (NFOR) and functional overreaching (FOR).

2.6. Establishment of the Functional Overreaching and Nonfunctional Overreaching Groups. The rats were empirically assigned to the NFOR and FOR groups based on their individual performances in $\mathrm{T} 4, \mathrm{~T} 5$, and $\mathrm{T} 6$. The test results were quantified by measuring the slope $(\alpha)$ of a least-squares fit line through the Pr for T4, T5, and T6. The critical slope value for group separation was obtained from the CO group from our previous study [4], which had a slope of $-3.26 \pm 11.79 \mathrm{~kg} \cdot \mathrm{m}$ (means $\pm \mathrm{SD}$ ). The critical value for separating the NFOR and FOR groups was the mean minus one standard deviation, that is, $\alpha_{\text {critical }}=-15.05 \mathrm{~kg} \cdot \mathrm{m}$. Figure 1 shows the histogram of the observed slopes. Rats with $\alpha<-15.05 \mathrm{~kg} \cdot \mathrm{m}$ were designated as NFOR $(n=8)$, and those with $\alpha \geq-15.05 \mathrm{~kg} \cdot \mathrm{m}$ were designated as FOR $(n=11)$.

2.7. Tissue and Blood Sample Collection. The animals were euthanized $48 \mathrm{~h}$ after T6 (Table 1) using a combination 
of the anesthetic Zoletil (50 mg/kg body weight) and the muscle relaxant xylazine ( 10 units/kg body weight), which was administered by intramuscular injection in the right quadriceps. Samples of blood, heart (left ventricle, LV), and red gastrocnemius ( $R G$ ) muscle were collected in that order from the CO, NFOR, and FOR groups.

2.8. Activity of Muscle Citrate Synthase and Mitochondrial Complexes $I / V$ and $I V / V$. Red gastrocnemius samples $(30 \mathrm{mg})$ were prepared as described by Zerbetto et al. [27] with the modifications described by Molnar et al. [28]. The samples were homogenized (Polytron PT-MR 2100 , Kinematica, Switzerland) in $2 \mathrm{~mL}$ of ice cold buffer (20 mM 3-(N-Morpholino) propanesulfonic acid (MOPS), $\mathrm{pH}$ 7.2, $440 \mathrm{mM}$ sucrose, $1 \mathrm{mM}$ ethylenediaminetetraacetic acid (EDTA), and $5 \mathrm{mM}$ phenylmethylsulfonyl fluoride (PMSF). The samples were centrifuged at $20,000 \times \mathrm{g}$ for 20 minutes. The supernatant was used to spectrophotometrically assay CS (EC 4.1.3.7) activity by determining the rate of the increase in absorbance at $412 \mathrm{~nm}$ due to the formation of thionitrobenzoic acid $\left(a=13.6 \mathrm{~mL} \cdot \mu \mathrm{mol}^{-1} \cdot \mathrm{cm}^{-1}\right)$ as described by Srere [29]. The pellet was resuspended in $80 \mu \mathrm{L}$ of buffer (1 M 6-aminohexanoic acid, $\mathrm{pH} 7.0$, $50 \mathrm{mM}$ BIS-TRIS, and $5 \mathrm{mM}$ PMSF) with $30 \mu \mathrm{L}$ of $10 \%$ n-dodecylmaltoside. This solution was centrifuged for 35 minutes at $100,000 \times \mathrm{g}$. The supernatant was collected, and the procedure was repeated to increase the sample yield. Both aliquots were mixed $(20 \mu \mathrm{L})$ and stored at $-80^{\circ} \mathrm{C}$.

The blue native polyacrylamide gel electrophoresis (BNPAGE) was performed as described by Schagger and von Jagow [30] using a $1 \times 70 \times 82 \mathrm{~mm}$ minigel (Mini-Protean, Bio-Rad). Following electrophoresis, the gels were cut into three pieces, each containing samples from one animal from each of the three experimental groups. The colorimetric analysis of the catalysis reactions (histochemistry) of complexes I and IV and the determination of the abundance of complex V (mitochondrial protein marker) were performed according to Molnar et al. [28].

The wet gels were digitally scanned using LABSCAN 5.0 software, and the histochemical staining intensity was quantified using the IMAGE MASTER 2D PLATINUM 6.0 software. The staining of complexes I and IV was measured as arbitrary units relative to the staining of complex $\mathrm{V}$ to allow the results to be analyzed both qualitatively and quantitatively as the specific activity.

2.9. Muscle and Heart Antioxidant Enzymes and TBARS Assays. The LV and RG sections (60 mg each) were frozen at $-80^{\circ} \mathrm{C}$ and later homogenized (Polytron PT-MR 2100, Kinematica, Switzerland) in an ice bath at maximum speed for $10 \mathrm{~s}$. The tissue was solubilized in a $1: 20(\mathrm{w} / \mathrm{v})$ ratio in $50 \mathrm{mM}$ phosphate buffer, $\mathrm{pH} 7.0$, to analyze catalase (EC 1.11.1.6), GR (EC 1.8.1.7) and total SOD (EC 1.15.1.1). An additional $90 \mathrm{mg}$ section was solubilized in a $1.15 \% \mathrm{KCl}$ solution at a $1: 10(\mathrm{w} / \mathrm{v})$ ratio for the thiobarbituric acidreactive substance (TBARS) analysis.

The catalase activity was determined according to Aebi [31] by the decrease in absorbance due to $\mathrm{H}_{2} \mathrm{O}_{2}$ consumption $\left(\stackrel{\circ}{=}=0.04 \mathrm{~mL} \cdot \mu \mathrm{mol}^{-1} \cdot \mathrm{cm}^{-1}\right)$ measured at $240 \mathrm{~nm}$. The glutathione reductase activity was quantified as described by Smith et al. [32] by the rate of the increase in absorbance at $412 \mathrm{~nm}$ due to the formation of thionitrobenzoic acid. One unit (U) of catalase, GR, and CS represents the activity in $\mu \mathrm{mol} / \mathrm{min}$.

The total SOD quantification was conducted with an R\&D Systems kit (MN, USA) according to the protocol of the manufacturer. One unit of SOD was defined as the activity that inhibits the rate of NBT-diformazan formation by $50 \%$.

TBARS was quantified similarly to the methods described by Uchiyama and Mihara [33] and Ohkawa et al. [34] using 1,1,3,3-tetramethoxypropane (TMP) as the standard. All analyses were performed in triplicate using a Beckman DU640 spectrophotometer. The means of the coefficients of variation $(\mathrm{CV})$ from the triplicate $\mathrm{LV}$ homogenate samples were $3.2 \%, 5.4 \%, 1.3 \%$ and $8.8 \%$ for catalase, GR, SOD, and TBARS, respectively. For RG muscle, we obtained CV values of $3 \%, 5.8 \%, 1.3 \%$, and $9.1 \%$ for catalase, GR, SOD, and TBARS, respectively.

2.10. Heart Histology. The heart was removed in diastole (filled with $1.15 \% \mathrm{KCl}$ ), cleaned with $0.9 \%$ saline solution at $4{ }^{\circ} \mathrm{C}$ to remove excess blood and weighed immediately following the cleaning. The left ventricle (LV) was fixed in $4 \%$ paraformaldehyde for $24 \mathrm{~h}$ and subsequently embedded in paraffin. The paraffin blocks were sectioned into $5 \mu \mathrm{m}$ slices using a microtome and were immediately mounted onto glass slides. The sections were stained with hematoxylin and eosin (HE) or picrosirius (sirius red 3BA in saturated picric acid solution), which was visualized without polarization. The cellular area and the LV collagen fibers were measured on the HE and Sirius Red slides, respectively. We quantified 30 cells on the HE slides and counted 30 fields from three animals of each experimental group on the Sirius Red slides. The cell area was determined in $\mu \mathrm{m}^{2}$, and the collagen area was measured as the percentage of total fields observed. The slide visualization and image recording were performed using an Olympus (USA) optic microscope, and the quantitative analysis was performed using Image ProPlus 6.0 (Amersham Biosciences).

2.11. Heart Apoptotic Index. A longitudinal section of the anterior portion of the LV was immersed in a 30\% sucrose solution at $4^{\circ} \mathrm{C}$ for $30 \mathrm{~min}$ for cryopreservation, embedded in Tissue-Tek, and stored at $-15^{\circ} \mathrm{C}$. Twelve consecutive 5 $\mu \mathrm{m}$ slices were cut in a cryostat (Leica, model CM1850, Germany) and placed on slides that had been previously coated with silane (methacryloxypropylmethoxysilane, Sigma, USA). The apoptotic index was obtained using the In Situ Cell Death Detection kit (Roche Diagnostics, Mannheim, Germany) and was calculated as the ratio of marked nuclei (apoptotic, brown) to nonmarked nuclei (nonapoptotic, purple). We used five optical fields from five animals in each experimental group for a total of 25 fields per group. The nuclei were counted using an Olympus (USA) microscope by an experienced researcher who was blinded to the identity of the samples. 


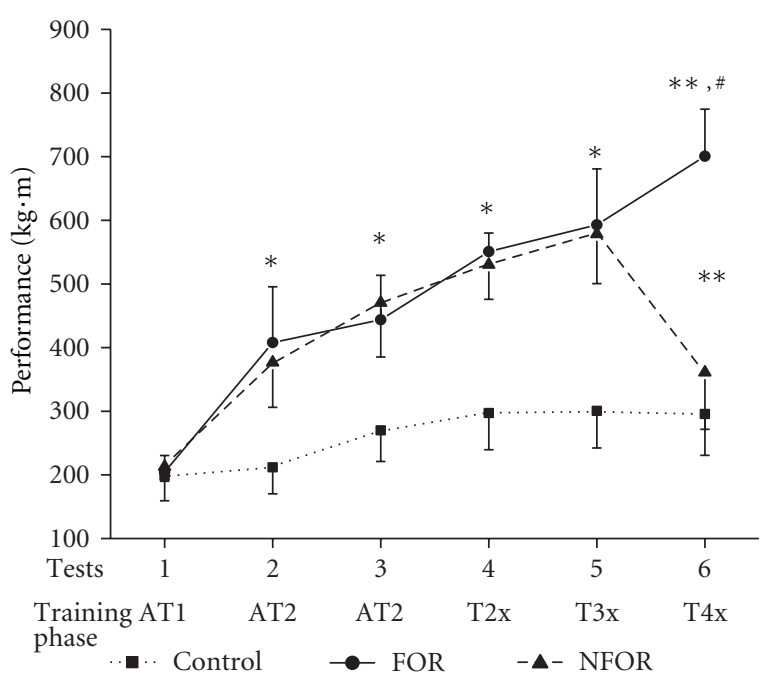

Figure 2: Performances of the CO $(n=9)$, FOR $(n=11)$ and NFOR $(n=8)$ groups in the six performance tests during the 11 -week running training protocol (means $\pm \mathrm{SD}$ ). ${ }^{*}$ Significant difference of the FOR and NFOR groups relative to the CO group $(P<0.001) .{ }^{* *}$ Significant difference between test 6 and test 5 in the paired analysis of FOR and NFOR groups $(P<0.01$ for FOR and $P<0.001$ for NFOR). "Significant difference of the FOR group relative to the NFOR and CO groups $(P<0.001)$.

2.12. Plasma Creatine Kinase and Lipid Peroxides. The blood was collected in heparin-coated tubes and was immediately centrifuged at $1,232 \times \mathrm{g}$ for 15 minutes at $4^{\circ} \mathrm{C}$ to separate the plasma. The plasma CK was measured by the CKNAC kit (Wiener Lab, Rosário, Argentina) using an Autolab Analyzer (Boehringer Mannheim, Germany), and the lipid peroxides were measured with a lipid peroxidation assay kit (Colorimetric Calbiochem kit, Frankfurt, Germany). This colorimetric assay is designed to measure malondialdehyde (MDA) in combination with 4-hydroxyalkenals. Malondialdehyde was used as the standard.

2.13. Statistical Analysis. The results are presented as the means \pm standard deviation (SD). We used the $t$-test to compare the differences between the means of two groups. To compare the means of more than two groups, we used unpaired ANOVA followed by Tukey's post hoc test. Comparisons with $P$-values less than 0.05 were considered significant.

\section{Results}

3.1. Performance. Both trained groups exhibited a significant increase in performance relative to the $\mathrm{CO}$ group throughout the protocol until the 10th week of training (Figure 2). When the training load was increased to four sessions a day $(\mathrm{T} 4 \mathrm{x})$, the performances of the trained rats differed. Some rats showed a significant performance increase in T6 relative to T5 (FOR group), whereas others showed a significant performance drop in T6 relative to T5 (NFOR group). There were no significant differences in the training volumes of the
NFOR and FOR groups until the 10th week (T3x). The total training volume of the NFOR group was significantly lower than that of the FOR group after the 11th week (T4x) (4348 $\pm 110 \mathrm{~min}$ and $4552 \pm 70 \mathrm{~min}$, resp., $P<0.01$ ).

3.2. Antioxidant Activities of SOD, Catalase, and GR and Concentration of TBARS in Muscle and Heart. The activities of SOD, catalase, and GR and the concentration of TBARS were significantly higher in the muscle of the NFOR group than in those of the $\mathrm{CO}$ and FOR groups (Figure 3). In the heart, the SOD activity of the NFOR group was significantly higher than that of the CO and FOR groups. The catalase activity of the NFOR group was significantly higher than that of the FOR group only. The GR activity of both trained groups, FOR and NFOR, was significantly higher than that of the $\mathrm{CO}$ group. Finally, there were no significant differences in the concentration of TBARS among the three groups.

Comparing heart with muscle within the $\mathrm{CO}$ group, we found that the activities of catalase and GR and the concentration of TBARS were significantly higher in the heart than in the muscle.

3.3. Activities of Muscle Citrate Synthase and Mitochondrial Complexes I/V and IV/V. The activity of CS was significantly higher in the FOR group than in the CO and NFOR groups (Table 2). The histochemical staining of complex I activity normalized to the complex $\mathrm{V}$ abundance (Complex I/V) was not significantly different between the groups. The equivalent analysis for complex IV/V staining produced a significantly lower value for the NFOR group than for the CO and FOR groups. The staining of complex IV was noticeably weaker for the individual samples from the NFOR group compared to the samples from the FOR and CO groups within the same gel.

3.4. Cardiac Morphometric Analysis. There was no significant difference in the heart mass between the different groups (Table 3). The ratio between the heart mass and the body mass was significantly greater for the FOR and NFOR groups than for the $\mathrm{CO}$ group. The cellular areas of tissue for the FOR and NFOR groups were significantly greater than that of the $\mathrm{CO}$ group.

\subsection{Histology of the Left Ventricle}

3.5.1. Hematoxylin and Eosin (HE) and Picrosirius (Sirius Red). Figure 4 shows representative HE (Figure 4(a)) and sirius red (Figure 4(b)) images of left ventricle tissue from an individual rat from each of the experimental groups. The HE staining did not reveal any observable differences in the LV cell structure among the CO, FOR, and NFOR groups. We did not discern any alterations related to the presence of cellular infiltration, as samples from all of the groups showed similar levels of this phenomenon in the peripheral region and around blood vessels. We did not observe cardiac steatosis. The sirius red staining did not reveal any quantitative differences in collagen between the different groups (Table 3). 
TABLE 2: Citrate synthase activity and specific activity (as arbitrary units) of complex I/V and IV/V in BN-PAGE gels.

\begin{tabular}{|c|c|c|c|}
\hline & $\mathrm{CO}$ & FOR & NFOR \\
\hline Citrate synthase (U/g wet) & $18 \pm 2$ & $35 \pm 3^{* *}$ & $21 \pm 7$ \\
\hline Complex I/V & $\mathrm{I} \longrightarrow$ & $1.06 \pm 0.40$ & $0.88 \pm 0.23$ \\
\hline Complex IV/V & $\mathrm{IV}-1.04 \pm 0.22$ & $1.06 \pm 0.22$ & $0.73 \pm 0.26^{*}$ \\
\hline
\end{tabular}

CO $(n=8)$. FOR $(n=8)$. NFOR $(n=8) .{ }^{*}$ Significantly different from CO and NFOR $(P<0.05) .{ }^{*}$ Significantly different from CO and NFOR $(P<0.001)$. Bands representing the histochemical staining of complexes I and IV and the protein content of complex V (Coomassie Blue G-250). Means \pm SD.

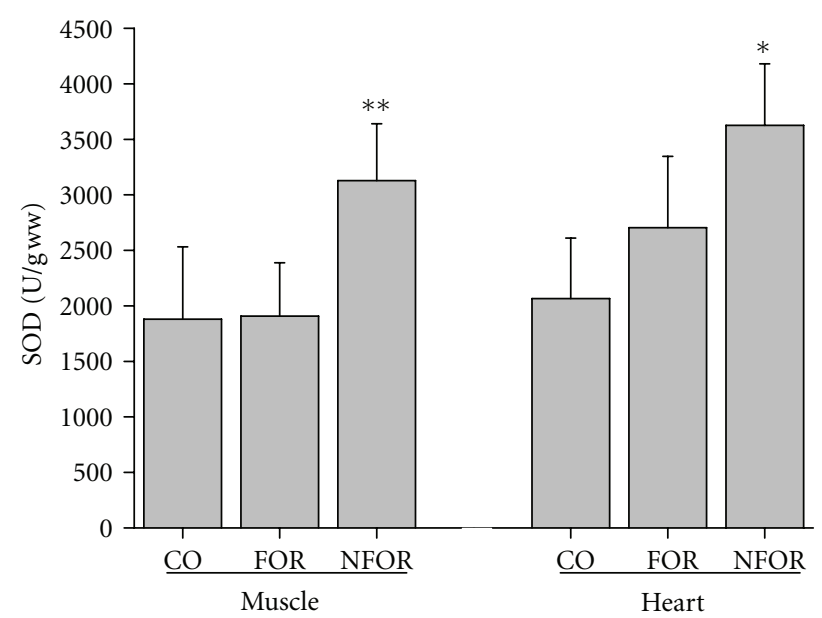

(a)

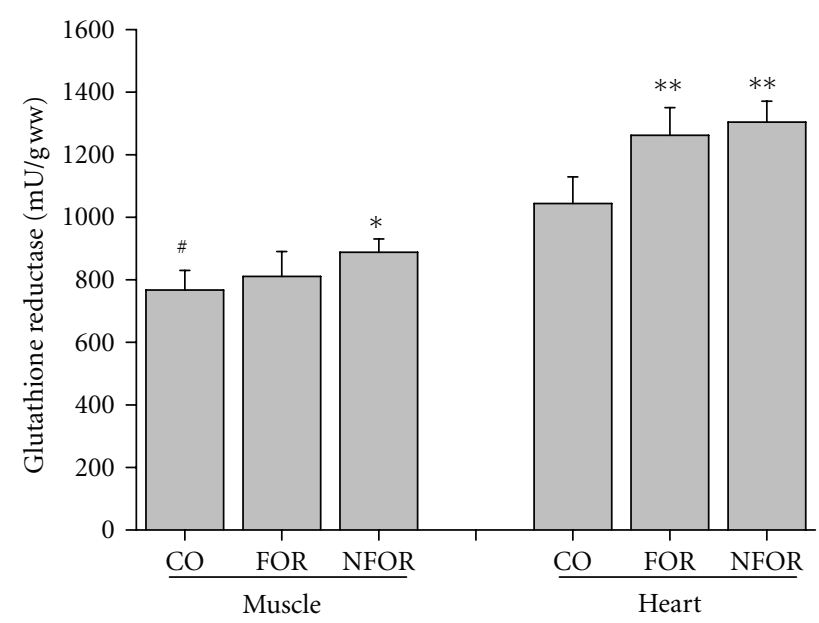

(c)

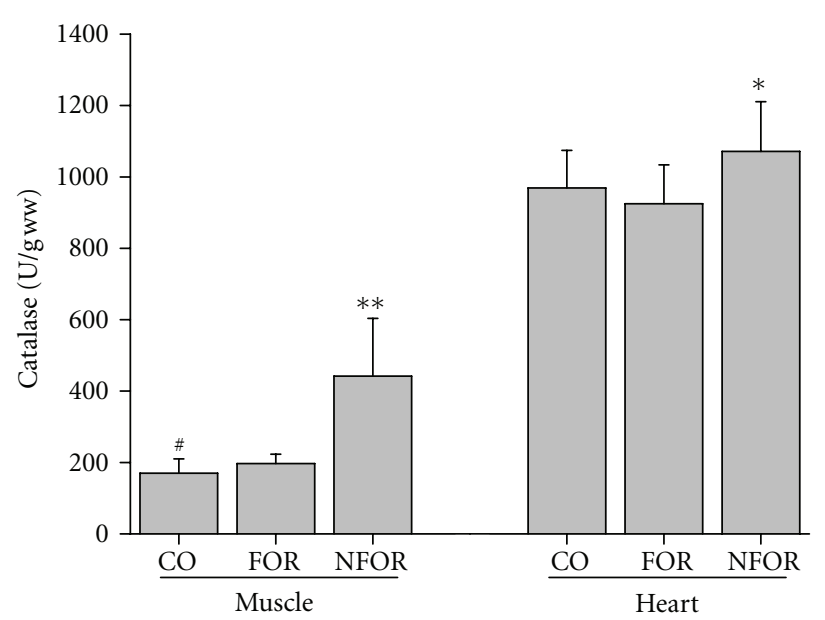

(b)

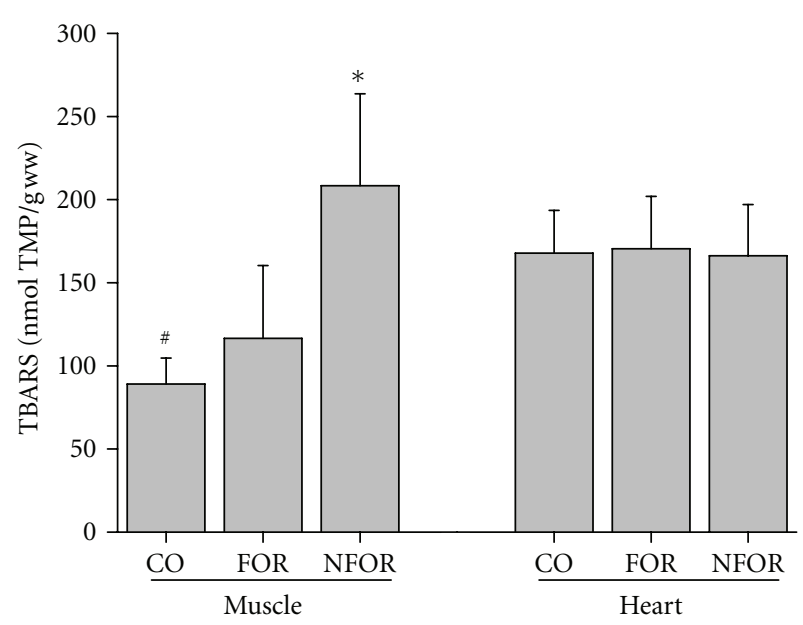

(d)

FIgURE 3: Activity of antioxidant enzymes and concentration of TBARS in heart and skeletal muscle tissue (means \pm SD). Comparisons were made between groups within the same tissue (muscle or heart) and between muscle and heart of the CO group. CO $(n=9)$, FOR $(n=11)$, and NFOR $(n=8)$. (a) SOD: $*$ difference with FOR $(P<0.05)$ and CO $(P<0.001)$; ** difference with FOR and CO $(P<0.001)$. (b) Catalase: * difference with FOR $(P<0.05)$; ${ }^{* *}$ difference with FOR and CO $(P<0.001)$; ${ }^{*}$ difference with CO heart $(P<0.001)$. $(\mathrm{c})$ GR: $*$ difference with FOR $(P<0.05)$ and CO $(P<0.01)$; ** difference with CO $(P<0.001)$; ${ }^{*}$ difference with CO heart $(P<0.001)$. $(\mathrm{d})$ TBARS:

* difference with FOR and CO $(P<0.001)$; ${ }^{*}$ difference with CO heart $(P<0.01)$. 
TABLE 3: Heart morphometric analysis.

\begin{tabular}{lcccc}
\hline & & CO & FOR & NFOR \\
\hline Cellular area & $\left(\mu \mathrm{m}^{2}\right)$ & $184.30 \pm 70.72$ & $220.85 \pm 59.39^{*}$ & $204.04 \pm 55.64^{*}$ \\
Collagen & $(\%)$ & $1.43 \pm 1.16$ & $1.56 \pm 1.42$ & $1.38 \pm 1.49$ \\
Heart mass & $(\mathrm{mg})$ & $1196.70 \pm 140.57$ & $1198.43 \pm 105.89$ & $1203.18 \pm 111.60$ \\
Body mass & $(\mathrm{g})$ & $416.20 \pm 41.14$ & $366.89 \pm 24.12^{*}$ & $370.29 \pm 33.03^{*}$ \\
Heart/body mass & $(\mathrm{mg} / \mathrm{g})$ & $2.88 \pm 0.22$ & $3.27 \pm 0.27^{*}$ & $3.25 \pm 0.17^{*}$ \\
\hline
\end{tabular}

Cellular area and collagen from the left ventricle: CO, FOR and NFOR $(n=3)$. A total of 30 cells (cellular area) and 30 fields (collagen) per animal were quantified, for a total of 90 cells and 90 fields per group. Heart mass and body mass: CO $(n=9)$, FOR $(n=11)$, NFOR $(n=8)$. ${ }^{*}$ Significantly different from $\mathrm{CO}(P<0.05)$. Mean \pm SD.

3.6. Apoptotic Index of the Left Ventricle. Figure 5 shows the apoptotic index of the left ventricle tissue. The ratio of the number of fields that showed apoptotic nuclei to the total number of fields quantified is displayed above the SD marker for each group. This ratio is an additional index of the proportional incidence of cardiomyocyte apoptosis in each group.

The NFOR group exhibited a significantly higher apoptotic index than the $\mathrm{CO}$ group. The number of positive stained fields (9 out of 25) highlights the increased incidence of apoptosis in the NFOR group. Additionally, apoptosis was observed in samples from four animals out of five in the NFOR group, whereas apoptosis was only observed in two FOR animals and just one $\mathrm{CO}$ animal.

3.7. Blood Biomarkers: CK and Lipid Peroxides. The plasma CK concentration was not changed in the FOR $(253 \pm$ $121 \mathrm{U} / \mathrm{L})$ or NFOR $(271 \pm 25 \mathrm{U} / \mathrm{L})$ groups compared with the $\mathrm{CO}(355 \pm 82 \mathrm{U} / \mathrm{L})$ group.

The plasma lipid peroxides were significantly higher $(P<$ $0.01)$ in the NFOR group $(1766 \pm 538 \mathrm{nmol} / \mathrm{L})$ compared to the CO $(925 \pm 190 \mathrm{nmol} / \mathrm{L})$ and FOR $(1018 \pm 249 \mathrm{nmol} / \mathrm{L})$.

\section{Discussion}

In the OT animal model used here, all of the animals in the FOR and NFOR groups showed the same progressive increase in performance relative to the same starting performance level (Figure 2) until the 10th training week, suggesting that both groups adapted similarly to the training protocol until that time (T3x; Table 1). The critical distinction between the results in the FOR and NFOR groups appeared with an increase in the daily training frequency (T4x; Table 1) at the 11th week. Therefore, our data showed that $\mathrm{OT}$ is necessary to maximize the increase in endurance performance for some individuals, as shown in the FOR group; however, it can be detrimental to the adaptive training process for other individuals, as shown in the NFOR group, due to the intrinsic characteristics of each animal that cannot be predicted by their initial performance level.

4.1. Muscle Analyses. Treadmill running had no effect on muscle catalase activity in the FOR group (Figure 3(b)). This result is consistent with previous studies on rats that provide little evidence for the ability of endurance exercise to increase catalase activity in skeletal muscle (10, 29). Other investigators, however, have reported reduced catalase activity resulting from exercise training [14, 35]. Similarly, the unchanged total SOD activity in the red gastrocnemius muscle of rats in the FOR group (Figure 3(a)) is consistent with a number of studies [16, 17, 36, 37], but other studies have shown increased SOD activity after exercise training $[38,39]$. These discrepancies could be explained by differences in training protocols, muscle fiber type composition $[17,40]$ or muscle recruitment pattern in different muscles. Hollander et al. [15] showed that the training induced upregulation of inner mitochondrial Mn$\mathrm{SOD}$, but not cytosolic $\mathrm{Cu} / \mathrm{Zn}-\mathrm{SOD}$, and catalase occurs primarily in type IIa fibers in the deep vastus lateralis after endurance training in rats. In contrast, Hollander et al. [15] also showed that in type I fibers in the soleus and in mixed fibers in the plantaris, there was no significant upregulation in antioxidant enzymes activities. The red gastrocnemius, plantaris and soleus are collectively referred to as the triceps surae muscle, and the plantaris muscle acts with the gastrocnemius [41]. The red gastrocnemius of Wistar rats is also a mixed fiber muscle [41]. Our data confirm that the mixed fiber type red gastrocnemius is less likely to show an increase in SOD and catalase after endurance training; these results are similar to those observed by others [17].

In contrast, we observed a significant increase in the activities of skeletal muscle SOD and catalase in the NFOR group when compared to the FOR and $\mathrm{CO}$ groups. Reactive oxygen species are involved in both transcriptional regulation and the increase expression of SOD and catalase $[42,43]$. Therefore, our data suggest that the increase in antioxidant enzymes activities in the NFOR group may reflect a specific adaptation to increased ROS production during the later stages of this OT protocol.

To date, no study has specifically shown the relationship between ROS, gene transcription and GR activity. Furthermore, there are fewer studies on GR adaptation to endurance training than those on SOD and catalase adaptation. In this study, the GR activity of the FOR group remained unchanged relative to $\mathrm{CO}$ (Figure 3(c)). In contrast, GR activity was increased in the NFOR group. Other studies [40, 44] showed that GR activity in rat skeletal muscle decreases after endurance training. The GR response presented here supports the argument that after severe endurance training, a more challenging prooxidant milieu was generated in the muscles of rats in the NFOR group, thus causing a higher 

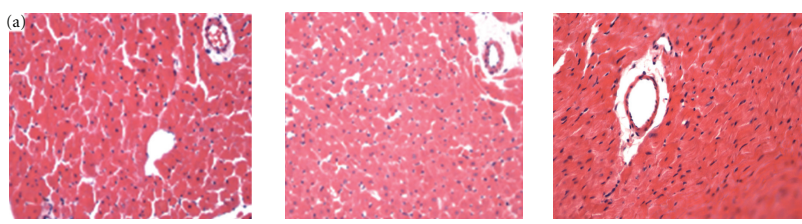

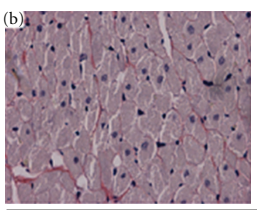

$\mathrm{CO}$

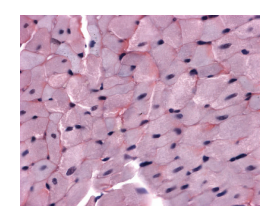

FOR

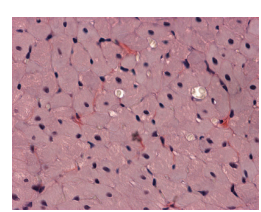

NFOR
Figure 4: Left ventricle histology of representative animals from each of the three experimental groups. (a) Hematoxylin and eosin (40x). (b) Sirius red (40x). There was no observable difference in the cell structure

antioxidant response adaptation. In addition, we observed a significant increase in muscle TBARS in the NFOR group compared to the CO and FOR groups (Figure $3(\mathrm{~d})$ ), suggesting increased lipid peroxides levels. The increase in muscle TBARS has not been frequently observed after endurance training; other studies have shown decreased or unchanged levels of TBARS in rat muscle [45-47], as we observed in the FOR group.

Complex IV of the electron transport chain, cytochrome c oxidase, is particularly vulnerable to ROS attack. Some authors have reported that an increase in markers of oxidative stress damage is associated with lower complex IV activity $[48,49]$. In this study, the activity of complex IV was lower in NFOR rats than in FOR rats (Table 2). Furthermore, when compared to $\mathrm{CO}$ rats, the specific activity staining of complex IV/V in the NFOR group showed a decreased activity after endurance OT. The oxidation of thiol groups $(-\mathrm{SH})$ in mitochondrial proteins by ROS may explain this lowered complex IV activity [50]. Analogously, oxidizing thiol groups within CS can also compromise its activity (Table 2), as shown experimentally by Ji et al. [51] after exhaustive exercise in rats. Complex I, however, may not be affected by ROS to the same extent that complex IV is. It has been suggested that several of the constituent subunits of complex I neutralize oxidative damage, thereby protecting the redox groups and stabilizing the core catalytic subunits $[52,53]$. Because of the differences in the structures of these two electron transport chain complexes and the sensitivity of these structures to ROS exposure, the BN-PAGE technique allowed individual identification of the abnormal activity of complex IV, as shown by others [54].

Taken together, lowered mitochondrial oxidative capacity after endurance training, increased activity of antioxidant enzymes in the RG muscle and increased lipid peroxide levels provide complementary evidence for a prooxidant alteration in muscle redox homeostasis associated with underperformance, particularly in the NFOR group. Our data for the NFOR group also suggest that the prooxidant cellular milieu in the RG muscle cannot be entirely avoided by the increase in activity of the antioxidant defense system

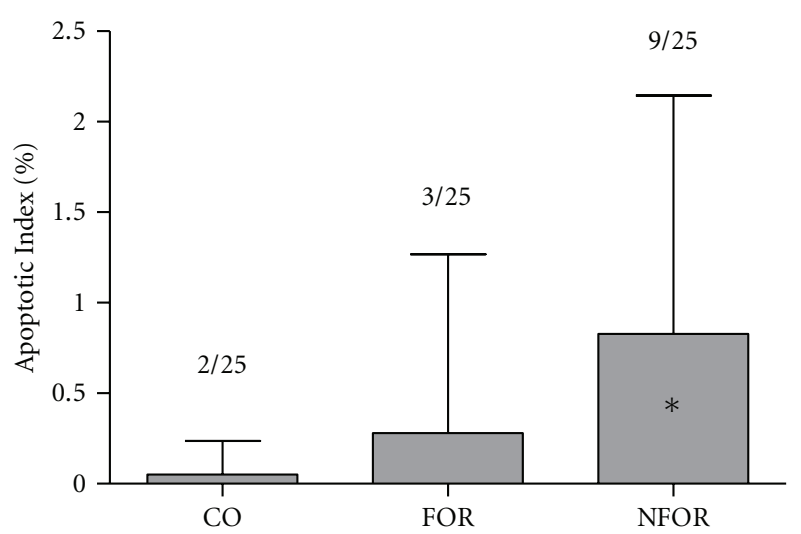

Figure 5: The apoptotic index of left ventricle from the CO $(n=5)$, FOR $(n=5)$, and NFOR $(n=5)$ groups (means $\pm \operatorname{SD})$. The ratio of the number of fields that showed apoptotic nuclei to the total number of fields quantified is displayed above the SD marker for each group. ${ }^{*}$ Significant difference relative to $\mathrm{CO}(P<0.05)$.

during endurance OT. Similarly, Franco et al. [55] have shown that rat muscle cells exposed to certain concentrations of ROS exhibit increased levels of not only the gene expression and activity of SOD and catalase but also of oxidized proteins. Therefore, a critical level of ROS production that can overcome the response of antioxidant enzymes to exercise may characterize muscle oxidative stress in subjects intolerant to severe endurance training.

4.2. Heart Analyses. Our results demonstrated that 11 weeks of endurance training had no effect on heart catalase activity in the FOR group (Figure 3(b)) and that the FOR group showed a trend of SOD activity upregulation compared to CO $(P=0.0523$, Figure 3(a)). Accordingly, Powers et al. [56] showed that the general adaptation to several endurancetraining protocols is characterized by SOD upregulation and unchanged catalase activity in the left ventricle. In agreement with muscle data, however, only the NFOR group presented a significant increase in the activities of both SOD and catalase in the heart.

Observing the CO group, the higher basal concentration of TBARS in the heart compared to muscle (Figure 3(d)) may illustrate a natural, elevated production of ROS by cardiac tissue [57]. However, when the NFOR group was subjected to endurance OT, the naturally higher GR and catalase activities of the heart, as shown by the CO group (Figures 3(b)-3(c)), and the further increase of SOD, catalase, and GR activities seem to be sufficient antioxidant adaptations to maintain the heart's redox homeostasis. The greater adaptation of antioxidant defense activity in the heart compared to muscle may have maintained the levels of TBARS observed in both the FOR and NFOR groups (Figure $3(\mathrm{~d})$ ). This finding is similar to the effect of moderate exercise on levels of TBARS previously reported by others [58-60].

The cardiac morphometric analysis showed no differences in heart mass among the CO, FOR and NFOR groups (Table 3). However, we noted a significant increase in the heart mass/body mass ratio in the FOR, and NFOR groups 
compared to the CO group. This increase resulted from a loss of bodyweight in the animals of both training groups during the protocol, as shown elsewhere [61]. Additionally, structural analysis of the left ventricle not only showed normal tissue architecture in the FOR and NFOR groups (Figure 4) but also showed remodeling due to increased cell area (i.e., cardiomyocyte hypertrophy) in trained animals compared to the CO group (Table 3). According to Fenning et al. [62], these adaptations improve contractile capacity in rats and lead to an optimization of cardiac function with a concomitant increase in cardiac output.

Despite the expected positive adaptation of cardiac function of trained rats, the increase in the apoptotic index for the NFOR group was significant compared to the CO group (Figure 5). Our data are comparable to the observations of Huang et al. [23], who have shown a preservation of the myocardial histological structure and an increase in apoptosis in the left ventricle of rats after an endurancetraining protocol. In contrast to the results of Huang et al. [23], however, we only observed significant cardiomyocyte apoptosis in the NFOR group which was vulnerable to muscle oxidative stress during severe endurance exercise.

4.3. Plasma CK and Lipid Peroxides. Plasma CK concentrations did not change in the FOR and NFOR groups compared to CO. This finding suggests that increased ROS production during exercise is not always related to severe muscle cell damage. Studies that induced electric contractile stimulation have shown that muscle cells rapidly generate ROS during exercise associated with little or no cell damage $[13,63]$. However, increased plasma CK is mainly related to the eccentric component in rat treadmill running $[64,65]$, the sloping run, which is not a relevant component of our training model. These observations also exclude subclinical chronic muscular damage as the cause for the chronic performance drop, which is a necessary condition to define the NFOR state [2].

The significant increase in plasma lipid peroxides in the NFOR group is in agreement with increased muscle TBARS. Many ROS (such as $\mathrm{NO}^{\bullet}, \mathrm{O}_{2}{ }^{--}$and $\mathrm{H}_{2} \mathrm{O}_{2}$ ) and reactive aldehydic products are membrane permeable and, as a result, are potentially able to diffuse into the surrounding medium $[18,66]$. However, it is not yet possible to exclude other sources of ROS in the NFOR group because other organs or blood cells, such as leukocytes and erythrocytes, may be additional sources of ROS during the exercise regimen [67]. In the context of the training protocol used here, lipid peroxide levels were more useful than CK as a blood biomarker to detect underperformance related to a prooxidant status.

\section{Conclusion}

To our knowledge, this is the first study showing that severe endurance exercise impairs mitochondrial adaptation related to oxidative stress in selective subjects. The persistent underperformance and the higher incidence of cardiomyocyte apoptosis in the NFOR group indicate that increasing training sessions and reducing recovery in the pursuit of high performance levels must be undertaken with caution. Our study also showed that blood biomarkers that are directly related to oxidative cellular damage can be used to identify individual vulnerability to oxidative stress during endurance OT, whereas CK, a frequently used marker of muscle tissue damage, may not be as effective in this case. Finally, the intrinsic characteristics that underlie the different adaptations to intense endurance training between the FOR and NFOR groups are currently only speculative. Our results support further studies with isolated mitochondria of NFOR rats to elucidate the intrinsic causes of subject-selected oxidative stress during severe endurance training.

\section{Authors' Contribution}

R. Ferraresso and R. de Oliveira contributed equally to this work.

\section{Acknowledgments}

The authors thank A. M. M. Porto for technical support. R. Ferraresso (07/57512-2) and R. de Oliveira (07/575116) received scholarships from FAPESP. R. Hohl received a postdoctoral fellowship grant from FAPESP (09/51125-2). This study was also supported by FUNCAMP (927.7-0100).

\section{References}

[1] S. O. Richardson, M. B. Andersen, and T. Morris, Eds., Overtraining Athletes: Personal Journeys in Sports, Human Kinetics, Champaign, Ill, USA, 2008.

[2] R. Meeusen, M. Duclos, M. Gleeson, G. Rietjens, J. Steinacker, and A. Urhausen, "Prevention, diagnosis and treatment of the Overtraining Syndrome. ECSS position statement 'task force," European Journal of Sport Science, vol. 6, no. 1, pp. 1-14, 2006.

[3] M. Lehmann, C. Foster, and J. Keul, "Overtraining in endurance athletes: a brief review," Medicine and Science in Sports and Exercise, vol. 25, no. 7, pp. 854-862, 1993.

[4] R. Hohl, R. L. P. Ferraresso, R. B. De Oliveira, R. Lucco, R. Brenzikofer, and D. V. De Macedo, "Development and characterization of an overtraining animal model," Medicine and Science in Sports and Exercise, vol. 41, no. 5, pp. 1155$1163,2009$.

[5] J. O. Holloszy and E. F. Coyle, "Adaptations of skeletal muscle to endurance exercise and their metabolic consequences," Journal of Applied Physiology Respiratory Environmental and Exercise Physiology, vol. 56, no. 4, pp. 831-838, 1984.

[6] I. Fridovich, "Mitochondria: are they the seat of senescence?" Aging Cell, vol. 3, no. 1, pp. 13-16, 2004.

[7] H. M. Alessio, "Exercise-induced oxidative stress," Medicine and Science in Sports and Exercise, vol. 25, no. 2, pp. 218-224, 1993.

[8] A. M. Hruszkewycz, "Evidence for mitochondrial DNA damage by lipid peroxidation," Biochemical and Biophysical Research Communications, vol. 153, no. 1, pp. 191-197, 1988.

[9] G. Paradies, G. Petrosillo, M. Pistolese, and F. M. Ruggiero, "Reactive oxygen species affect mitochondrial electron transport complex I activity through oxidative cardiolipin damage," Gene, vol. 286, no. 1, pp. 135-141, 2002.

[10] S. Raha† and B. H. Robinson, "Mitochondria, oxygen free radicals, and apoptosis," American Journal of Medical Genetics, vol. 106, no. 1, pp. 62-70, 2001. 
[11] Y. Zhang, O. Marcillat, C. Giulivi, L. Ernster, and K. J. A. Davies, "The oxidative inactivation of mitochondrial electron transport chain components and ATPase," Journal of Biological Chemistry, vol. 265, no. 27, pp. 16330-16336, 1990.

[12] H. Sies, Oxidative Stress, Academic Press, London, UK, 1985.

[13] A. McArdle, D. Pattwell, A. Vasilaki, R. D. Griffiths, and M. J. Jackson, "Contractile activity-induced oxidative stress: cellular origin and adaptive responses," American Journal of Physiology, vol. 280, no. 3, pp. C621-C627, 2001.

[14] M. Higuchi, L. J. Cartier, M. Chen, and J. O. Holloszy, "Superoxide dismutase and catalase in skeletal muscle: adaptive response to exercise," Journals of Gerontology, vol. 40, no. 3, pp. 281-286, 1985.

[15] J. Hollander, R. Fiebig, M. Gore et al., "Superoxide dismutase gene expression in skeletal muscle: fiber-specific adaptation to endurance training," American Journal of Physiology, vol. 277, no. 3, pp. R856-R862, 1999.

[16] M. H. Laughlin, T. Simpson, W. L. Sexton, O. R. Brown, J. K. Smith, and R. J. Korthuis, "Skeletal muscle oxidative capacity, antioxidant enzymes, and exercise training," Journal of Applied Physiology, vol. 68, no. 6, pp. 2337-2343, 1990.

[17] S. K. Powers, D. Criswell, J. Lawler et al., "Influence of exercise and fiber type on antioxidant enzyme activity in rat skeletal muscle," American Journal of Physiology, vol. 266, no. 2, pp. R375-R380, 1994.

[18] S. K. Powers and M. J. Jackson, "Exercise-induced oxidative stress: cellular mechanisms and impact on muscle force production," Physiological Reviews, vol. 88, no. 4, pp. 12431276, 2008.

[19] P. M. Tidus, "Radical species in inflammation and overtraining," Canadian Journal of Physiology and Pharmacology, vol. 76, pp. 553-538, 1998.

[20] L. L. Ji, "Antioxidants and oxidative stress in exercise," Proceedings of the Society for Experimental Biology and Medicine, vol. 222, pp. 283-292, 1999.

[21] K. George, R. Shave, D. Warburton, J. Scharhag, and G. Whyte, "Exercise and the heart: can you have too much of a good thing?" Medicine and Science in Sports and Exercise, vol. 40, no. 8, pp. 1390-1392, 2008.

[22] J. M. Scott and D. E. R. Warburton, "Mechanisms underpinning exercise-induced changes in left ventricular function," Medicine and Science in Sports and Exercise, vol. 40, no. 8, pp. 1400-1407, 2008.

[23] C. C. Huang, T. J. Lin, C. C. Chen, and W.-T. Lin, "Endurance training accelerates exhaustive exercise-induced mitochondrial DNA deletion and apoptosis of left ventricle myocardium in rats," European Journal of Applied Physiology, vol. 107, no. 6, pp. 697-706, 2009.

[24] M. J. Jackson, S. Papa, J. Bolaños et al., "Antioxidants, reactive oxygen and nitrogen species, gene induction and mitochondrial function," Molecular Aspects of Medicine, vol. 23, no. 1-3, pp. 209-285, 2002.

[25] B. Chabi, V. Ljubicic, K. J. Menzies, J. H. Huang, A. Saleem, and D. A. Hood, "Mitochondrial function and apoptotic susceptibility in aging skeletal muscle," Aging Cell, vol. 7, no. 1, pp. 2-12, 2008.

[26] R. Hohl, L. A. S. Nunes, R. A. Reis et al., "Glutamine and glutamate reference intervals as a clinical tool to detect training intolerance during training and overtraining," in An International Perspective on Topics in Sports Medicine and Sports Injury, K. Zaslav, Ed., pp. 41-64, 2012.

[27] E. Zerbetto, L. Vergani, and F. Dabbeni-Sala, "Quantification of muscle mitochondrial oxidative phosphorylation enzymes via histochemical staining of blue native polyacrylamide gels," Electrophoresis, vol. 18, no. 11, pp. 2059-2064, 1997.

[28] A. M. Molnar, A. A. Alves, L. Pereira-da-Silva, D. V. Macedo, and F. Dabbeni-Sala, "Evaluation by blue native polyacrylamide electrophoresis colorimetric staining of the effects of physical exercise on the activities of mitochondrial complexes in rat muscle," Brazilian Journal of Medical and Biological Research, vol. 37, no. 7, pp. 939-947, 2004.

[29] P. A. Srere, "Citrate synthase," Methods in Enzymology, vol. 13, pp. 3-11, 1969.

[30] H. Schagger and G. von Jagow, "Blue native electrophoresis for isolation of membrane protein complexes in enzymatically active form," Analytical Biochemistry, vol. 199, no. 2, pp. 223231, 1991.

[31] H. Aebi, "Catalase in vitro," Methods in Enzymology, vol. 105, pp. 121-126, 1984.

[32] I. K. Smith, T. L. Vierheller, and C. A. Thorne, "Assay of glutathione reductase in crude tissue homogenates using 5,5'dithiobis(2-nitrobenzoic acid)," Analytical Biochemistry, vol. 175, no. 2, pp. 408-413, 1988.

[33] M. Uchiyama and M. Mihara, "Determination of malonaldehyde precursor in tissues by thiobarbituric acid test," Analytical Biochemistry, vol. 86, no. 1, pp. 271-278, 1978.

[34] H. Ohkawa, N. Ohishi, and K. Yagi, "Assay for lipid peroxides in animal tissues by thiobarbituric acid reaction," Analytical Biochemistry, vol. 95, no. 2, pp. 351-358, 1979.

[35] S. V. Brooks, A. Vasilaki, L. M. Larkin, A. McArdle, and M. J. Jackson, "Repeated bouts of aerobic exercise lead to reductions in skeletal muscle free radical generation and nuclear factor $\kappa \mathrm{B}$ activation," Journal of Physiology, vol. 586, no. 16, pp. 39793990, 2008.

[36] H. M. Alessio and A. H. Goldfarb, "Lipid peroxidation and scavenger enzymes during exercise: adaptive response to training," Journal of Applied Physiology, vol. 64, no. 4, pp. 1333-1336, 1988.

[37] L. L. Ji, F. W. Stratman, and H. A. Lardy, "Antioxidant enzyme systems in rat liver and skeletal muscle," Archives of Biochemistry and Biophysics, vol. 263, no. 1, pp. 150-160, 1988.

[38] R. Jenkins, "The role of superoxide dismutase and catalase in muscle fatigue," in Biochemistry of Exercise, H. Knuttgen, Ed., vol. 13, pp. 467-471, Human Kinetics, Champaign, Ill, USA, 1983.

[39] A. T. Quintanilha, "Effects of physical exercise and/or vitamin E on tissue oxidative metabolism," Biochemical Society Transactions, vol. 12, no. 3, pp. 403-404, 1984.

[40] C. Leeuwenburgh, J. Hollander, S. Leichtweis, M. Griffiths, M. Gore, and L. L. Ji, "Adaptations of glutathione antioxidant system to endurance training are tissue and muscle fiber specific," American Journal of Physiology, vol. 272, no. 1, pp. R363-R369, 1997.

[41] J. L. Morales-López, E. Agüera, F. Miró, and A. Diz, "Variations in fibre composition of the gastrocnemius muscle in rats subjected to speed training," Histology and Histopathology, vol. 5, no. 3, pp. 359-364, 1990.

[42] L. L. Ji, "Antioxidant signaling in skeletal muscle: a brief review," Experimental Gerontology, vol. 42, no. 7, pp. 582-593, 2007.

[43] L. Z.-H. Zhou, A. P. Johnson, and T. A. Rando, "NF $\kappa$ B and AP-1 mediate transcriptional responses to oxidative stress in skeletal muscle cells," Free Radical Biology and Medicine, vol. 31, no. 11, pp. 1405-1416, 2001.

[44] C. K. Sen, E. Marin, M. Kretzschmar, and O. Hänninen, "Skeletal muscle and liver glutathione homeostasis in response 
to training, exercise, and immobilization," Journal of Applied Physiology, vol. 73, no. 4, pp. 1265-1272, 1992.

[45] A. Frankiewicz-Jóźko, J. Faff, and B. Sieradzan-Gabelska, "Changes in concentrations of tissue free radical marker and serum creatine kinase during the post exercise period in rats," European Journal of Applied Physiology and Occupational Physiology, vol. 74, no. 5, pp. 470-474, 1996.

[46] R. A. Pinho, M. E. Andrades, M. R. Oliveira et al., "Imbalance in SOD/CAT activities in rat skeletal muscles submitted to treadmill training exercise," Cell Biology International, vol. 30, no. 10, pp. 848-853, 2006.

[47] Z. Radák, T. Kaneko, S. Tahara et al., "The effect of exercise training on oxidative damage of lipids, proteins, and DNA in rat skeletal muscle: evidence for beneficial outcomes," Free Radical Biology and Medicine, vol. 27, no. 1-2, pp. 69-74, 1999.

[48] A. Navarro, C. Gomez, J. M. López-Cepero, and A. Boveris, "Beneficial effects of moderate exercise on mice aging: survival, behavior, oxidative stress, and mitochondrial electron transfer," American Journal of Physiology, vol. 286, no. 3, pp. R505-R511, 2004.

[49] P. K. Thomas, J. M. Cooper, R. H. King et al., "Myopathy in vitamin E deficient rats: muscle fibre necrosis associated with disturbances of mitochondrial function," Journal of Anatomy, vol. 183, no. 3, pp. 451-461, 1993.

[50] H. Michel, J. Behr, A. Harrenga, and A. Kannt, "Cytochrome c oxidase: structure and spectroscopy," Annual Review of Biophysics and Biomolecular Structure, vol. 27, pp. 329-356, 1998.

[51] L. L. Ji, F. W. Stratman, and H. A. Lardy, "Enzymatic down regulation with exercise in rat skeletal muscle," Archives of Biochemistry and Biophysics, vol. 263, no. 1, pp. 137-149, 1988.

[52] J. Hirst, J. Carroll, I. M. Fearnley, R. J. Shannon, and J. E. Walker, "The nuclear encoded subunits of complex I from bovine heart mitochondria," Biochimica et Biophysica Acta, vol. 1604, no. 3, pp. 135-150, 2003.

[53] U. Schulte, V. Haupt, A. Abelmann et al., "A reductase/isomerase subunit of mitochondrial NADH: ubiquinone oxidoreductase (complex I) carries an NADPH and is involved in the biogenesis of the complex," Journal of Molecular Biology, vol. 292, no. 3, pp. 569-580, 1999.

[54] M. A. Calvaruso, J. Smeitink, and L. Nijtmans, "Electrophoresis techniques to investigate defects in oxidative phosphorylation," Methods, vol. 46, no. 4, pp. 281-287, 2008.

[55] A. A. Franco, R. S. Odom, and T. A. Rando, "Regulation of antioxidant enzyme gene expression in response to oxidative stress and during differentiation of mouse skeletal muscle," Free Radical Biology and Medicine, vol. 27, no. 9-10, pp. 11221132, 1999.

[56] S. K. Powers, D. Criswell, J. Lawler et al., "Rigorous exercise training increases superoxide dismutase activity in ventricular myocardium," American Journal of Physiology, vol. 265, no. 6, pp. H2094-H2098, 1993.

[57] C. D. Phung, J. A. Ezieme, and J. F. Turrens, "Hydrogen peroxide metabolism in skeletal muscle mitochondria," Archives of Biochemistry and Biophysics, vol. 315, no. 2, pp. 479-482, 1994.

[58] A. Ascensão, J. Magalhães, J. M. C. Soares et al., "Endurance training limits the functional alterations of heart rat mitochondria submitted to in vitro anoxia-reoxygenation," International Journal of Cardiology, vol. 109, no. 2, pp. 169-178, 2006.

[59] A. Ascensão, J. Magalhães, J. M. C. Soares et al., "Moderate endurance training prevents doxorubicin-induced in vivo mitochondriopathy and reduces the development of cardiac apoptosis," American Journal of Physiology, vol. 289, no. 2, pp. H722-H731, 2005.

[60] M. Gul, B. Demircan, S. Taysi et al., "Effects of endurance training and acute exhaustive exercise on antioxidant defense mechanisms in rat heart," Comparative Biochemistry and Physiology, vol. 143, no. 2, pp. 239-245, 2006.

[61] M. Morán, J. Delgado, B. González, R. Manso, and A. Megías, "Responses of rat myocardial antioxidant defences and heat shock protein HSP72 induced by 12 and 24-week treadmill training," Acta Physiologica Scandinavica, vol. 180, no. 2, pp. 157-166, 2004.

[62] A. Fenning, G. Harrison, D. Dwyer, R. R. Meyer, and L. Brown, "Cardiac adaptation to endurance exercise in rats," Molecular and Cellular Biochemistry, vol. 251, no. 1-2, pp. 51-59, 2003.

[63] C. A. O'Neill, C. L. Stebbins, S. Bonigut, B. Halliwell, and J. C. Longhurst, "Production of hydroxyl radicals in contracting skeletal muscle of cats," Journal of Applied Physiology, vol. 81, no. 3, pp. 1197-1206, 1996.

[64] J. M. Davis, E. A. Murphy, M. D. Carmichael et al., "Curcumin effects on inflammation and performance recovery following eccentric exercise-induced muscle damage," American Journal of Physiology, vol. 292, no. 6, pp. R2168-R2173, 2007.

[65] J. Komulainen and V. Vihko, "Exercise-induced necrotic muscle damage and enzyme release in the four days following prolonged submaximal running in rats," Pflugers Archiv European Journal of Physiology, vol. 428, no. 3-4, pp. 346-351, 1994.

[66] H. Esterbauer, K. H. Cheeseman, M. U. Dianzani, G. Poli, and T. F. Slater, "Separation and characterization of the aldehydic products of lipid peroxidation stimulated by $\mathrm{ADP}-\mathrm{Fe}^{2+}$ in rat liver microsomes," Biochemical Journal, vol. 208, no. 1, pp. 129-140, 1982.

[67] M. G. Nikolaidis and A. Z. Jamurtas, "Blood as a reactive species generator and redox status regulator during exercise," Archives of Biochemistry and Biophysics, vol. 490, no. 2, pp. 7784, 2009. 


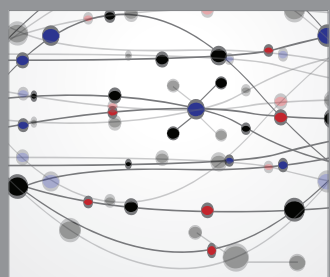

The Scientific World Journal
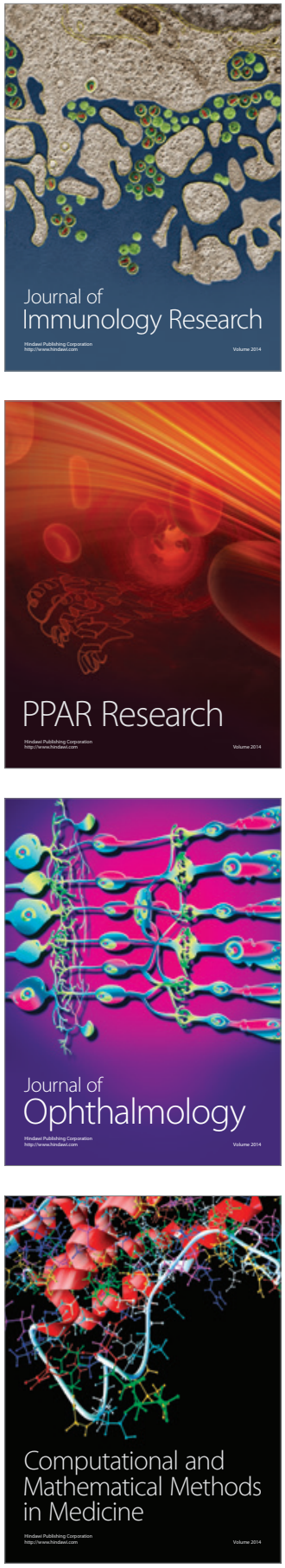

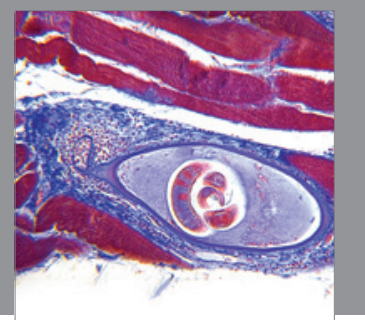

Gastroenterology

Research and Practice
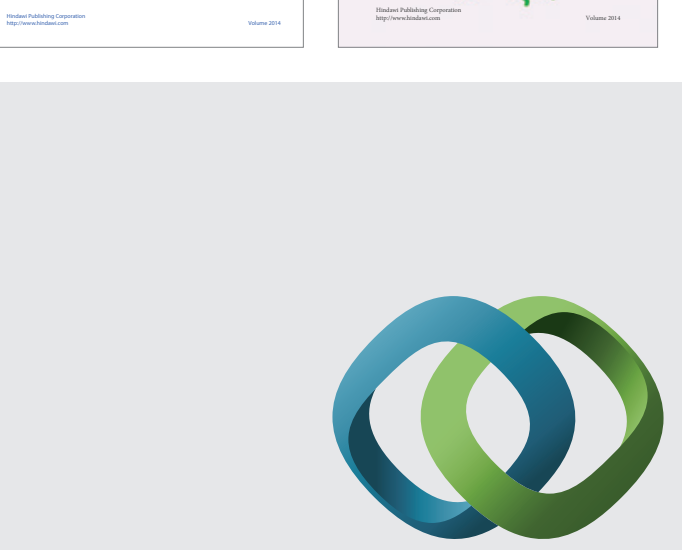

\section{Hindawi}

Submit your manuscripts at

http://www.hindawi.com
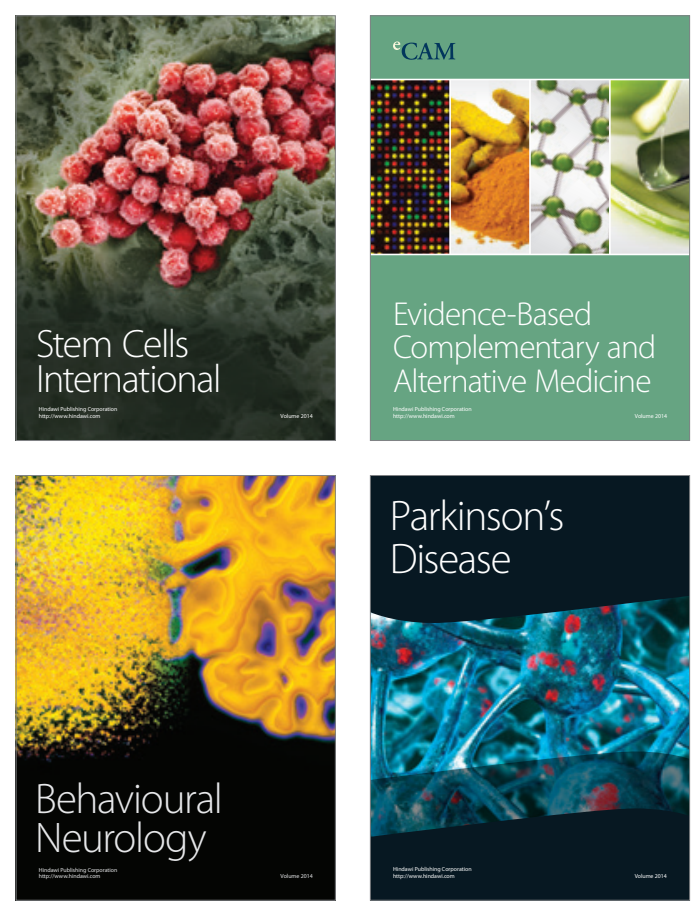

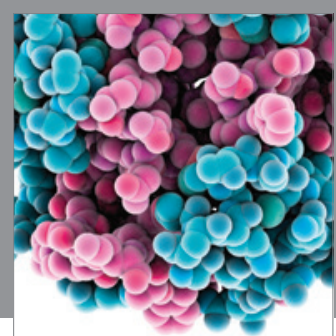

Journal of
Diabetes Research

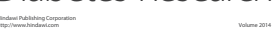

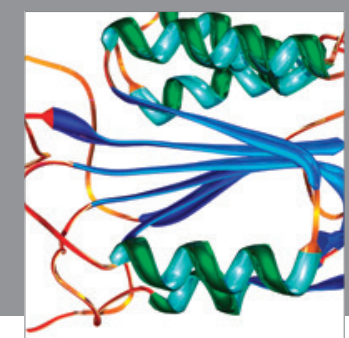

Disease Markers
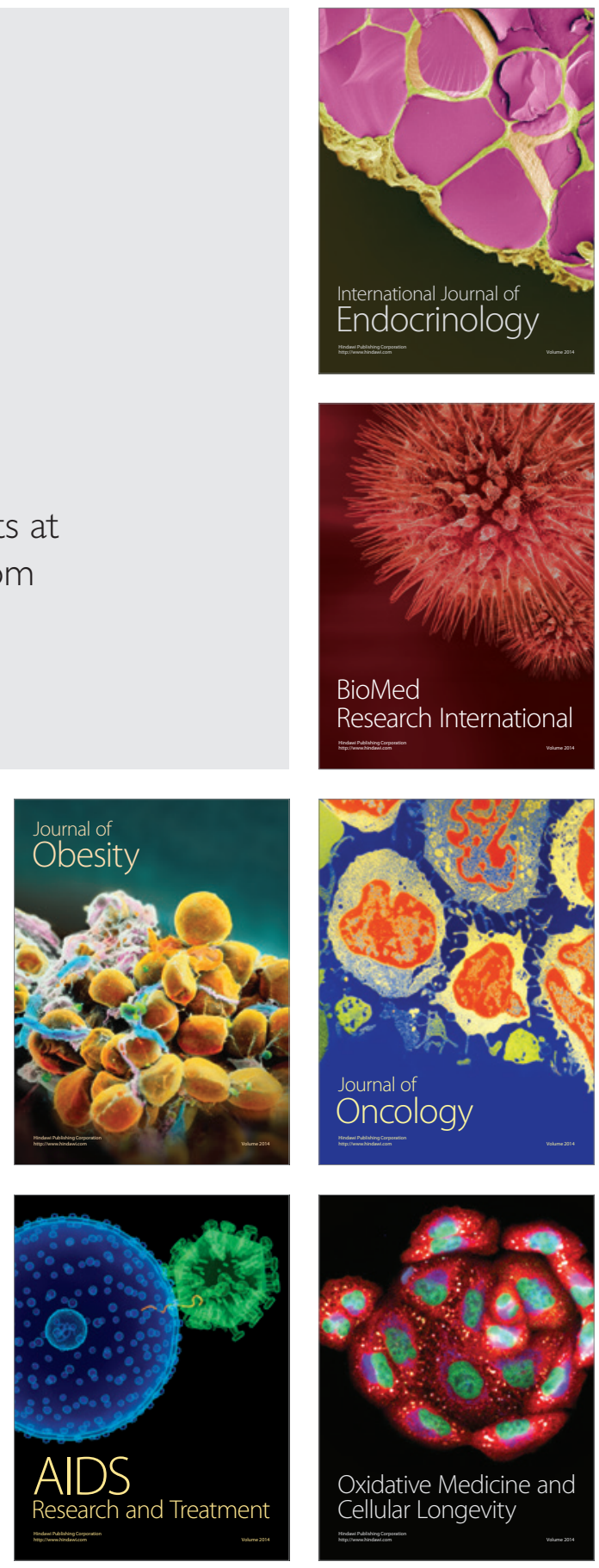